\title{
Volatile profile of heated soybean oil treated with quercetin and chlorogenic acid
}

\author{
Perfil de compostos voláteis do óleo de soja aquecido e tratado com quercetina e ácido clorogênico
}

\author{
Adriana Leão de MIRANDA ${ }^{1}$, Mariana Carvalho RIBEIRO ${ }^{1}$, \\ Ricardo Felipe Alves MOREIRA ${ }^{1}$, Carlos Alberto Bastos de MARIA ${ }^{1 *}$
}

\begin{abstract}
Changes in the profile of volatile compounds after the heating of refined soybean oil without adding antioxidants, and treated with quercetin and chlorogenic acid (5-CQA) were investigated by GC/FID, GC/MS, and GC/SNIFFING. The heating temperature of the oil sample was $20{ }^{\circ} \mathrm{C}$ for the first minute, and then it was increased up to $160^{\circ} \mathrm{C}$ at the rate of $10{ }^{\circ} \mathrm{C} \mathrm{min}{ }^{-1}$. The final temperature was kept for 10 minutes. 19 volatiles were identified in the heated samples without antioxidants. Medium-chain carbonyls predominated in the volatile fraction, mainly 2-heptenal, 2,4-heptadienal and 2,4-decadienal. Around 11 to 15 volatile compounds were detected in the heated samples treated with 5-CQA and quercetin, respectively. 5-CQA was not very efficient in delaying the formation of oxidative volatile compounds. The samples quercetin presented lower proportion of carbonyls with $\mathrm{C}_{6}-\mathrm{C}_{9}$. The $G C$ peak area data were used as an approach to estimate the relative content of each volatile compound and indicate that the samples treated with quercetin $(\mathrm{p}<0.05)$ had significantly lower values for, 1-pentanol, 2,4-heptadienal, and 2,4-decadienal compared with those without antioxidants and treated with 5-CQA. GC/SNIFFING analysis revealed a smaller odor perception in the samples treated with 5-CQA compared to those without antioxidants. No odor was perceived in the heated samples treated with quercetin. These results indicate greater effectiveness of quercetin in delaying the formation of oxidative volatile compounds in soybean oils subjected to mild heating conditions. Apparently, biopolyphenols used in the present work showed good oxidative stability since no new volatile compound was detected in the heated samples treated with them.
\end{abstract}

Keywords: soybean oil; GC/MS; oxidative volatiles; quercetin; chlorogenic acid.

\section{Resumo}

As alterações no perfil de compostos voláteis, após o aquecimento de óleo de soja refinado sem a adição de antioxidantes e tratado previamente com quercetina e ácido clorogênico (5-ACQ), foram investigadas através da CG/DIC, CG/EM e CG/SNIFFING. A temperatura de aquecimento do óleo foi de $20^{\circ} \mathrm{C}$ no primeiro minuto e aumentada até $160{ }^{\circ} \mathrm{C}$ à taxa de $10{ }^{\circ} \mathrm{C} \mathrm{min}{ }^{-1}$. A temperatura final foi mantida por 10 minutos. Um total de 19 compostos voláteis foi identificado nas amostras aquecidas sem a adição de antioxidantes. As carbonilas de cadeia média predominaram na fração volátil. Cerca de 15 e 11 compostos voláteis foram detectados no óleo aquecido com adição prévia de quercetina e 5-ACQ, respectivamente. As amostras tratadas com quercetina mostraram uma menor proporção de carbonilas com esqueletos de carbono $\mathrm{C}_{6}-\mathrm{C}_{9}$. A composição estimada de compostos voláteis mostrou que amostras tratadas com quercetina tiveram valores significativamente $(\mathrm{p}<0,05)$ menores para 1-pentanol, 2,4-heptadienal e 2,4-decadienal em comparação com as amostras sem antioxidantes adicionados e com as tratadas com 5-ACQ. A análise por meio de CG/SNIFFING revelou um número menor de odores em amostras tratadas com 5-ACQ em comparação àquelas sem tratamento algum. Nenhum odor foi percebido nas amostras aquecidas com adição prévia de quercetina. Estes resultados indicam uma maior efetividade da quercetina no retardamento do processo oxidativo em amostras de óleo de soja sujeitas a aquecimento a $160^{\circ} \mathrm{C} \pm 10^{\circ} \mathrm{C} \mathrm{min}{ }^{-1}$ por 10 minutos. Aparentemente, os compostos fenólicos naturais usados neste trabalho mostraram boa estabilidade oxidativa, já que nenhum composto volátil novo foi detectado nas amostras aquecidas e tratadas com eles.

Palavras-chave: ácido clorogênico; CG/EM; compostos voláteis; óleo de soja; quercetina.

\section{Introduction}

Refined edible oils containing substantial amounts of polyunsaturated fatty acids undergo oxidative rancidity and produce off-flavors. Autoxidation is a major route of oil rancidity and its progression occurs via a free radical chain mechanism (SHERWIN, 1976). The addition of primary antioxidants (e.g. polyphenolic compounds) retards the autoxidation process by acting as chelators of transition metals and/or as hydrogen donors and produces relatively stable free radicals and non-radical products (HAMILTON et al., 1997). Synthetic phenolic compounds (e.g. TBHQ) are the most commonly antioxidants used in lipids. However, there is a tendency of consumer groups to decrease the amount of synthetic additives in foods. As a consequence, naturally occurring phenolic compounds (e.g. flavonoids and phenolic acids) have drawn attention because they have been ingested for centuries and are assumed to be relatively safe for human consumption. Indeed, the daily dietary intake of these natural components is approximately $1 \mathrm{~g}$ via the ingestion of vegetables (LIU, 2004). Quercetin (flavonol) and chlorogenic acid (5-CQA) (cinnamate) are typical phenolic compounds widely distributed in plants including many foods and beverages. In recent years, these biophenolic compounds have proved to provide protective

Recebido para publicação em 6/8/2007

Aceito para publicação em 20/3/2008 (002735)

Laboratório de Química de Alimentos - LQA, Instituto Biomédico, Universidade Federal do Estado do Rio de Janeiro - UNIRIO, Rua Frei Caneca, 94, $4^{\circ}$ andar, CEP 20211-040, Cidade Nova - RJ, Brazil, E-mail: carreb@uol.com.br

${ }^{*}$ A quem a correspondência deve ser enviada 
effects against oxidative stress in animal and in vitro models (ZHANG et al., 2006; MORALES et al., 2006). Reactive oxygen species appear to be major contributors in the pathogenesis of degenerative diseases such as arteriosclerosis, cancer, and chronic inflammation.

In a previous work, some studies were performed aiming at elucidating the effectiveness of 5-CQA and quercetin in stabilizing refined soybean oil subjected to accelerated oxidation (MAGDA et al., 1997; MAGDA et al., 1998; DE MARIA et al., 2000). Chemical analysis of the oxidized oil samples included the determinations of the peroxide values (PV), the conjugated dienes at $233 \mathrm{~nm}$ (MAGDA et al., 1997; MAGDA et al., 1998), and the induction time obtained using an oxidative stability index instrument (DE MARIA et al., 2000). It was observed that primary antioxidative action of quercetin was greater than that of 5-CQA. In fact, results from another investigation have shown that quercetin is effective in delaying rancidity in canola oil (WANASUNDARA; SHAHIDI, 1994).

Nevertheless, the effect of natural phenolic antioxidants on the volatile profile of soybean oil submitted to forced oxidation has not been thoroughly studied yet. These biophenols could modify the volatile fraction not only by affecting the oxidative formation of volatile compounds, but also by providing volatiles through their thermal degradation. The present work aim is to study changes in the volatile profile of refined soybean oils treated with quercetin and 5-CQA and submitted to mild heating conditions.

\section{Materials and methods}

\subsection{Materials}

Reagents: Quercetin and 5-CQA were from Sigma (St. Louis, MO, USA). Tenax TA was from Supelco (Bellefonte, PA, USA). Absolute ethanol was from Merck (Darmstadt, Germany). All other chemicals were from Aldrich (Sheboygan, WI, USA).

Samples: Three fresh refined soybean oil samples were obtained from Cargill Agrícola S.A. (Brazil). The good quality of the samples was confirmed by the fatty acid composition and PV analysis (MAGDA et al., 1997).

\subsection{Methods}

Sample preparation: Due to the low solubility of the phenolic compounds in soybean oil, it was necessary to dissolve them in absolute ethanol. Quercetin or 5-CQA $(40 \mathrm{mg}$ ) was dissolved in $1 \mathrm{~mL}$ of ethanol in a magnetic stirrer, added to the oil $(120 \mathrm{~mL})$, and mixed until dissolution. The sample without antioxidants contained the same amount of ethanol as the one that was used to dissolve the additives. Samples without adding antioxidants and with quercetin or 5-CQA were placed in a $10 \mathrm{~cm}$ diameter flat Teflon-coated pan (with deep of $4 \mathrm{~cm}$ ) with flared sides and subjected to accelerated oxidation, as follows: the oil sample temperature was $20^{\circ} \mathrm{C}$ for the first minute and then it was increased

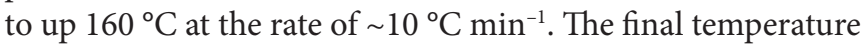
was kept for 10 minutes. The skillet was heated in a hot plate connected to an electronic thermometer used to regulate the temperature of the sample. Each heated sample was cooled at room temperature for 30 minutes and immediately submitted to the enrichment of the headspace fraction.

Isolation of the headspace volatile fraction: $100 \mathrm{~mL}$ oil sample was placed in a $500 \mathrm{~mL}$ Pyrex heavy-walled filtering flask with a side hose-connection (Brand, Wertheim, Germany), o.d. $10 \mathrm{~mm}$, and heated at $60^{\circ} \mathrm{C}$ under stirring. Purified nitrogen $\left(0.9-1.0 \mathrm{~L} \mathrm{~min}^{-1}\right)$ was passed through this system for 2 hours, and the entrained volatiles were adsorbed on a Tenax trap. This adsorvent was previously conditioned in a oven at $225^{\circ} \mathrm{C}$ for 3 hours under a $\mathrm{N}_{2}$ flow of $0.9-1.0 \mathrm{~L} \mathrm{~min}^{-1}$. Desorption of the compounds was done with $200 \mathrm{~mL}$ of acetone. This volume was settled by monitoring $10 \mathrm{~mL}$ aliquots of acetone until no more volatiles could be detected using GC/FID. The eluate was then concentrated to $200 \mu \mathrm{L}$ in a rotatory evaporator at $20^{\circ} \mathrm{C}$.

GC/FID: A Carlo Erba 4300 GC equipped with a $30 \mathrm{~m} \times 0.25 \mathrm{~mm}$ i.d. $\times 0.25 \mu \mathrm{m}$ Supelcowax ${ }^{\mathrm{TM}} 10$ fused-silica polar capillary column (Supelco, Milford, USA) was used. The injector and FID temperatures were 230 and $240^{\circ} \mathrm{C}$, respectively. Helium was used as the carrier gas at $0.83 \mathrm{~mL} \mathrm{~min}^{-1}$ rate. The oven temperature ranged from 50 to $230{ }^{\circ} \mathrm{C}$ at $3{ }^{\circ} \mathrm{C} \mathrm{min}{ }^{-1}$. The split ratio was 1:20. Linear retention indices (LRI) were estimated using the modified Kövatz method (VAN DEN DOOL; KRATZ, 1963). All oil samples were analyzed in two replicates. The GC peak area data were used as an approach to estimate the relative content of each volatile compound. The mean, standard deviation, and one-way analysis of variance $(\mathrm{p}<0.05)$ were performed using a statistical graphics system (STSC, 1986).

GC/MS: A Shimadzu GC-17A/QP5050 quadrupole mass spectrometry with National Institute of Standards and Technology (NIST) 12.lib and 62.lib data system was used. The instrument was operated in the electron ionization mode at $70 \mathrm{eV}$, taking scans from 20 to $300 \mathrm{~m} / \mathrm{z}$ in a $1 \mathrm{~s}$ cycle. The column and chromatographic conditions were the same as described for the GC/FID analysis. Tentative identification of the volatiles was based on the comparison of the mass spectra of unknown compounds against NIST library data. Wherever possible, the results were confirmed by comparison with authentic substances. Only the compounds identified using at least reference standards and mass spectra data were considered to be definitively identified.

CG/SNIFFING: The same above-mentioned chromatographic conditions were used, splitting the effluent of the capillary column (1:10) between FID, and the artisanal sniffing port. Odor port evaluation was carried out freely by two testers.

\section{Results and discussion}

\subsection{PV analysis}

The PV of the fresh oil was $0.7 \pm 0.02$ meq. $\mathrm{L}^{-1}$ which proved the good quality of the product (MAGDA et al., 1997). On the other hand, there were differences in PV of in the heated oil samples containing quercetin $\left(12 \pm 0.4\right.$ meq. $\left.\mathrm{L}^{-1}\right)$ and 5-CQA (13 $\left.\pm 0.5 \mathrm{meq} \cdot \mathrm{L}^{-1}\right)$ to those without antioxidants $\left(17 \pm 0.7\right.$ meq. $\left.L^{-1}\right)$. Therefore, the addition of either quercetin or 5-CQA was capable of delaying oil peroxide formation. 


\subsection{Volatile profile}

Changes in the volatile profile after the heating of refined soybean oil without antioxidants and treated with quercetin and 5-CQA were investigated. The estimated composition of volatiles in the headspace fraction is shown in Table 1 . No recovery method or GC standardization were applied, and thus, the data presented are estimated values. A total of 19 volatile compounds were identified in the heated soybean oil without antioxidants. Among them, $63 \%$ were definitively identified by comparing the retention time and mass spectral data with those of authentic standards. The chief oxidative volatile compounds were aldehydes, especially 2 -heptenal, 2,4-heptadienal, and 2,4decadienal. The detection of 2-heptenal and 2,4-decadienal in the soybean oil samples is in accordance with reports from other authors (KAO et al., 1998; STEENSON et al., 2002). On the other hand, this is the first time, to our knowledge, that 2,4-heptadienal was detected in heated soybean oil. As previously reported, 2,4-heptadienal was detected during the autoxidation of methyl linolenate at room temperature (ULLRICH; GROSCH, 1987). In another study, tri cis,cis 9,15-linoleoylglycerol was submitted to accelerated oxidation forming allylic radicals that reacted with $\mathrm{O}_{2}$ forming monohydroperoxides at the $\mathrm{C}_{8}-\mathrm{C}_{11}$ positions (NEFF; SELKE, 1993). These monohydroperoxides could undergo additional reactions to produce oxidative volatiles. Thus, the occurrence of 2,4-heptadienal and 2,4-decadienal in heated soybean oil may be attributed to the thermal decomposition of 8, 9, 10 and 11 hydroperoxides of linoleic and linolenic esters.

A total of 15 and 11 oxidative volatile compounds were detected in heated soybean oil treated with 5-CQA and quercetin, respectively (Table 1). In general, 5-CQA was not very efficient in delaying oxidative volatile formation. The addition of quercetin, on the other hand, increased the oxidative stability of the heated oil samples. The estimated concentration of the volatiles by means of relative GC peak areas showed that soybean oil samples treated with quercetin had significantly lower values for 1-pentanol, 2,4-heptadienal, and 2,4-decadienal in comparison with those without antioxidants and treated with 5-CQA. Furthermore, samples treated with quercetin exhibited a lower proportion of aldehydes with $\mathrm{C}_{6}-\mathrm{C}_{9}$ skeletons. A previous study reported that $14,15,16$, and 17 monohydroperoxides were expected precursors of medium-chain carbonyls (NEFF; SELKE, 1993). These monohydroperoxides are derived from the oxidation of allylic radicals at the $\mathrm{C}_{15-16}$ position. Then, it is possible that quercetin reduces the formation of oxidative volatiles by acting as an inhibitor of the oxidation of allylic radicals or by delaying the thermal decomposition of the monohydroperoxides previously formed. These findings are in accordance with previous data from our laboratory (DE MARIA et al., 2000), which showed that the antioxidative potency of quercetin was significantly greater than that of 5-CQA. The structural characteristics imparting the highest antioxidant activity in the quercetin was found to be the following (DE BEER et al., 2002): a) the ortho 3',4'-dihydroxy moiety in the B'-ring; b) the 2,3-double bond in combination with the 4-keto group; and c) the 3-and 5-hydroxyl groups in the $\mathrm{C}$ - and A-ring. These characteristics favor the electron delocalisation in the C-ring promoting maximum scavenging potential. In contrast to quercetin, 5-CQA contains only a 3', '-dihydroxy group in the aromatic ring (caffeic acid moiety) (Figure 1).

\subsection{Odor perception}

Aroma concentrates obtained from the headspace of heated soybean oil samples by adsorptive column chromatography,

Table 1. Volatile composition of heated soybean oil samples without antioxidants and treated 5-CQA and quercetin.

\begin{tabular}{|c|c|c|c|c|c|c|c|}
\hline Compounds & \multicolumn{3}{|c|}{$\begin{array}{c}\text { Samples } \\
\text { Percentual area }(\text { Mean } \pm \text { SD) }\end{array}$} & \multicolumn{3}{|c|}{ Odor perception } & LRI \\
\hline Heptanal $^{a}$ & $0.30 \pm 0.06^{\alpha}$ & $0.29 \pm 0.02^{\alpha}$ & nd & slightly green & slightly green & nd & 1164 \\
\hline Octanal $^{\mathrm{a}}$ & $<0.01$ & nd & nd & nd & nd & nd & 1238 \\
\hline 1-pentanol ${ }^{\mathrm{a}}$ & $1.50 \pm 0.30^{\alpha}$ & $1.13 \pm 0.15^{\alpha}$ & $0.57 \pm 0.15^{\beta}$ & nd & nd & nd & 1248 \\
\hline 2-heptenal ${ }^{\mathrm{a}}$ & $3.20 \pm 0.45^{\alpha}$ & $4.03 \pm 0.15^{\beta}$ & $3.10 \pm 0.30^{\alpha}$ & nd & nd & nd & 1295 \\
\hline 1-hexanol ${ }^{\mathrm{a}}$ & $<0.01$ & $<0.01$ & $<0.01$ & nd & nd & nd & 1352 \\
\hline 7-octen-4-ol ${ }^{\mathrm{b}}$ & $0.29 \pm 0.005^{\alpha}$ & $0.32 \pm 0.07^{\alpha}$ & $0.10 \pm 0^{\beta}$ & nd & nd & nd & 1438 \\
\hline 2,4-heptadienal ${ }^{\mathrm{a}}$ & $2.77 \pm 0.45^{\alpha}$ & $2.20 \pm 0.20^{\alpha}$ & $1.17 \pm 0.30^{\beta}$ & strongly oil & oily & nd & 1446 \\
\hline 2-nonenal ${ }^{\mathrm{a}}$ & $<0.01$ & $<0.01$ & $<0.01$ & nd & nd & nd & 1515 \\
\hline 2,4-dimethyl-cyclohexanol ${ }^{\mathrm{b}}$ & $<0.01$ & $<0.01$ & nd & oily & oily & nd & 1526 \\
\hline 2-undecenal ${ }^{\mathrm{b}}$ & $0.53 \pm 0.15^{\alpha}$ & $0.50 \pm 0.1^{\alpha}$ & $0.34 \pm 0.04^{\alpha}$ & nd & nd & nd & 1743 \\
\hline 2,4-decadienal ${ }^{a}$ & $1.50 \pm 0.26^{\alpha}$ & $1.33 \pm 0.15^{\alpha}$ & $0.67 \pm 0.06^{\beta}$ & heated oil & heated oil & nd & 1806 \\
\hline hexanoic acid ${ }^{a}$ & $<0.01$ & $<0.01$ & $<0.01$ & unpleasant & nd & nd & 1847 \\
\hline
\end{tabular}


<smiles>O=c1c(O)c(-c2ccc(O)c(O)c2)oc2cc(O)cc(O)c12</smiles><smiles>[CH]</smiles><smiles>O=C1CC2C(C(=O)O)CC(O)C(O)(C1)C2O</smiles>

Figure 1. Chemical structures of biopolyphenols. a) quercetin; and b) chlorogenic acid (5-CQA).

followed by desorption with acetone, provided similar odors to those of the original samples. The perceived odor qualities obtained by means of the GC-SNIFFING technique are showed in Table 1. Different odors emanated from the heated soybean oil samples without antioxidants were related to the volatile compounds previously identified by GC/MS. Among these, heptanal had a slightly green odor, while 2,4-heptadienal, decenal, and 2,4-decadienal had a intense oily odor. These findings are in accordance with those from previous works which reported similar odor notes to heptanal (GASSER; GROSCH, 1988), 2,4heptadienal, and 2,4-decadienal (ULLRICH; GROSCH, 1987) in different model systems.

Oil samples treated with 5-CQA provided less odoriferous notes in comparison with those without antioxidants while no odor was perceived when samples treated with quercetin were analyzed. Probably, the concentrations of the volatiles in the samples treated with quercetin were below the perception threshold.

\section{Conclusion}

The results mentioned above indicate the greater effectiveness of quercetin in delaying the formation of oxidative volatile compounds in soybean oil samples subjected to mild heating conditions. Apparently, the biopolyphenolic compounds used in the present work showed good oxidative stability since no new volatile compounds were detected in the heated samples treated with them.

\section{Acknowledgments}

The authors are grateful for the financial support provided by the Fundação de Amparo a Pesquisa do Rio de Janeiro (FAPERJ) and Conselho Nacional de Desenvolvimento Científico e Tecnológico (CNPq).

\section{References}

BEER, D. et al. Phenolic Compounds: A Review of their Possible Role as In Vivo Antioxidants of Wine. South African Journal of Enolology Viticulture, v. 23, n. 2, p. 48-61, 2002.

DE MARIA, C. A. B. et al. Stabilization of Soybean Oil with Heated Quercetin and 5-Caffeoylquinic Acid in the Presence of Ferric Ion. Journal of Agricultural and Food Chemistry, v. 48, n. .9, p. 3935-3938, 2000.

GASSER, U.; GROSCH, W. Identification of Volatile Flavour Compounds with High Aroma Values from Cooked Beef. Zeitschrift für Lebensmittel - Untersuchung und Forschung A, v. 186, p. 489-494, 1988.

HAMILTON, R. J. et al. Chemistry of Free Radicals in Lipids. Food Chemistry, v. 60, n. 2, p. 193-199, 1997.

KAO, J. W.; HAMMOND, E. G.; WHITE, P. J. Volatile Compounds Produced During Deodorization of Soybean Oil and their Flavor Significance. Journal of the American Oil Chemists' Society, v. 75, n. 9, 1103-1107, 1998.

LIU, R. H. Potential Synergy of Phytochemicals in Cancer Prevention: Mechanism of Action. Journal of Nutrition, v. 134, n. 12, p. 3479S-3485S, 2004.

MAGDA, R. L. et al. Effect of 5-Caffeoylquinic Acid on Soybean Oil Oxidative Stability. International Journal of Food Science and Technology, v. 32, n. 1, p. 75-79, 1997.

MAGDA, R. L. et al. Effect of the 5-Caffeoylquinic Acid in the Presence of Metal Chelators on Soybean Oil Oxidative Stability. Lebensmittel Wissenschaft Und - Technologie, v. 31, n. 1, p. 64-68, 1998.

MORALES, A. I. et al. Protective Effect of Quercetin on Experimental Chronic Cadmium Nephrotoxicity in Rats is Based on its Antioxidant Properties. Food Chemistry And Toxicology, v. 44, p. 2092-2100, 2006.

NEFF, W. E.; SELKE, E. Volatile Compounds from the Triacylglycerol of cis, cis 9,15-Linoleic Acid. Journal of the American Oil Chemists' Society, v. 70, n. 2, p. 157- 161, 1993.

SHERWIN, E. R. Antioxidants for Vegetable Oils. Journal of the American Oil Chemists' Society, v. 53, p. 430-436, 1976.

STEENSON, D. F.; LEE, J. H.; MIN, D. B. Solid Phase Microextraction of Volatile Soybean Oil and Corn Oil Compounds. Journal of Food Science, v. 67, n. 1, p. 71-76, 2002.

STSC. Statistical Graphics System. MD: Statistical Graphic Corporation, 1986.

ULLRICH, F.; GROSCH, W. Identification of the Most Intense Volatile Flavour Compounds Formed During Autoxidation of Linoleic Acid. Zeitschrift für Lebensmittel - Untersuchung und Forschung A, v. 184, p. 277-282, 1987.

Van den DOOL, H.; KRATZ, P. D. A Generalization of the Retention Index System Including Linear Temperature Programmed GasLiquid Partition Chromatography. Journal of Chromatography, v. 11, p. 463-471, 1963.

WANASUNDARA, U. N.; SHAHIDI, F. Stabilization of canola oil with flavonoid. Food Chemistry, v. 50, p. 393-396, 1994.

ZHANG, J. et al. Free Radical Scavenging and Cytoprotective Activities of Phenolic Antioxidants. Molecular Nutrition \& Food Research, v. 50, p. 996-1005, 2006. 